Clinical interventions for patients with type 2 diabetes according to whether their New Zealand cardiovascular risk score was given in the notes

\begin{tabular}{|c|c|c|c|c|}
\hline \multirow[b]{2}{*}{ Intervention } & \multicolumn{2}{|c|}{ All patients } & \multicolumn{2}{|c|}{ High risk patients (>20\% five year risk) } \\
\hline & $\begin{array}{c}\text { No }(\%, 95 \% \text { Cl) of patients } \\
\text { with score }(n=162)\end{array}$ & $\begin{array}{c}\text { No }(\%, 95 \% \mathrm{Cl}) \text { of control } \\
\text { patients }(\mathrm{n}=161)\end{array}$ & $\begin{array}{c}\text { No }(\%, 95 \% \text { Cl) of patients } \\
\text { with score }(n=86)\end{array}$ & $\begin{array}{c}\text { No }(\%, 95 \% \mathrm{CI}) \text { of control } \\
\text { patients }(\mathrm{n}=82)\end{array}$ \\
\hline Change in diabetes treatment & $68(42 \%, 34 \%$ to $50 \%)$ & $58(36 \%, 29 \%$ to $45 \%)$ & $38(44 \%, 35 \%$ to $54 \%)$ & $29(35 \%, 24 \%$ to $47 \%)$ \\
\hline Change in antihypertensive drugs & $26(16 \%, 10 \%$ to $22 \%)$ & $17(10 \%, 5 \%$ to $16 \%)$ & $20 \star(23 \%, 15 \%$ to $31 \%)$ & $8(10 \%, 3 \%$ to $17 \%)$ \\
\hline Change in lipid lowering drugs & $20(12 \%, 7 \%$ to $17 \%)$ & $14(9 \%, 4 \%$ to $14 \%)$ & $17^{\star}(20 \%, 12 \%$ to $27 \%)$ & $7(9 \%, 2 \%$ to $15 \%)$ \\
\hline Referral to dietician & $17(10 \%, 6 \%$ to $15 \%)$ & $21(13 \%, 7 \%$ to $19 \%)$ & $9(10 \%, 5 \%$ to $16 \%)$ & $6(7 \%, 1 \%$ to $17 \%)$ \\
\hline Other & $20(12 \%, 7 \%$ to $17 \%)$ & $15(9 \%, 5 \%$ to $15 \%)$ & $10(12 \%, 6 \%$ to $18 \%)$ & $10(12 \%, 4 \%$ to $20 \%)$ \\
\hline Risk score mentioned in letter to general practitioner & $10(6 \%, 3 \%$ to $10 \%)$ & $3(2 \%,-1 \%$ to $4 \%)$ & $10(12 \%, 6 \%$ to $18 \%)$ & $3(4 \%,-1 \%$ to $8 \%)$ \\
\hline Total No of interventions & 161 & 128 & 104 & 63 \\
\hline
\end{tabular}

${ }^{\star} \mathrm{P}=0.01$ compared with control group by the Mantel-Haenszel test.

significant differences between control and experimental groups in the primary outcome measures (table): change of diabetes treatment $(36 \% v 42 \%)$, lipid lowering drugs $(9 \%$ v 12\%), or blood pressure drugs (10\% v $16 \%)$ and referral to dietician $(13 \% v 10 \%)$. There were no differences in other interventions between the control and experimental groups. Among high risk patients, however, those in the experimental group were more likely to be prescribed blood pressure and lipid lowering drugs than those in the control group $(\mathrm{P}<0.02$, Mantel-Haenszel test). Despite this difference, the time until the next hospital outpatient appointment was the same in the two groups, with $24 \%$ in each group (39 in the experimental group and 38 in the control group) receiving an appointment in less than six months.

\section{Comment}

We found that clear documentation of a cardiovascular risk score in the notes increased prescribing of risk modifying drugs for patients with diabetes who are at high risk of cardiovascular disease. More high risk patients in the experimental group were prescribed both blood pressure lowering and lipid lowering drugs. However, there was no increase in prescribing for patients at relatively low risk.
Although individual risk factors such as blood pressure, smoking status, and lipid concentrations are generally available in clinics, integrated cardiovascular risk scores are often not calculated because of lack of time. This leaves the clinician with complex clinical data that can be difficult to interpret and are thus often not acted on. Our results indicate that it is worth developing clinical support systems that will calculate cardiovascular risk before the consultation.

We thank Dr S Ogston for statistical advice.

Contributors: GPL designed the study, wrote the protocol, and helped to write the paper. LMLH conducted the study and wrote the paper. RTJ helped analyse the data and write the paper.

Funding: None.

Competing interests: None declared.

1 Haffner SM, Lehto S, Ronnemaa T, Pyorala K, Laako M. Mortality from coronary heart disease in subjects with type 2 diabetes and in nondiabetic subjects with and without prior myocardial infarction. $N$ Engl J Med 1998;339:229-34.

2 European Action on Secondary Prevention by Intervention to Reduce Events I and II Group. Clinical reality of coronary prevention guidelines: a comparison of EUROASPIRE I and II in nine countries. Lancet 2001;357:995-1001.

3 United Kingdom Prospective Diabetes Study Group. Tight blood pressure control and risk of macrovascular and microvascular complications in type 2 diabetes (UKPDS 38). BMJ 1998;317:703-13.

4 LaRosa JC, Vupputuri S. Effect of statins on risk of coronary disease: Meta-analysis of randomised controlled trials. JAMA 1999;282:2340-6.

5 Jackson R. Updated New Zealand cardiovascular disease risk-benefit prediction guide. BMJ 2000;320:709-10.

(Accepted 18 April 2002)

\title{
Discrepancies between patients' assessments of outcome: qualitative study nested within a randomised controlled trial
}

\author{
Rona Campbell, Brian Quilty, Paul Dieppe
}

Department of Social Medicine, University of Bristol, Bristol BS8 2PR

Rona Campbell lecturer in health services research

continued over BMJ 2003;326:252-3

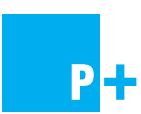

Examples of interviews with patients appear on bmi.com
Assessments of therapeutic effectiveness should not rely exclusively on clinical data, but they should include patient based outcome measures. A plethora of generic and disease specific measures is now available to collect such data by questionnaire, and well developed methods for testing the precision of such measures exist. ${ }^{2}$ Another method of collecting patient based outcome data is by in-depth interview. A randomised controlled trial to test the effectiveness of a package of physiotherapy treatment (nine treatment sessions involving patellar taping, seven different exercises, correction of posture, and advice on footwear) for patellofemoral osteoarthritis, which included a nested qualitative study of 20 participants randomised to the intervention arm, provided an opportunity to compare the two approaches to collecting outcome data: quantitatively by questionnaire and qualitatively by means of in-depth interview. ${ }^{3}$

\section{Participants, methods, and results}

The primary outcome measure was pain in the worse knee, recorded on a $10 \mathrm{~cm}$ visual analogue scale in the presence of $\mathrm{BQ}$. We used the function subscale of the Western Ontario and McMaster Universities' osteoarthritis index (WOMAC), a validated, disease specific, patient based measure, as a secondary outcome measure. ${ }^{5}$ An experienced interviewer undertook the in-depth interviews after the treatment but before the main follow up visit of the trial. Interviews were 
Questionnaire and interview based patient assessments of pain and disability after package of physiotherapy treatment for osteoarthritis of the knee

\begin{tabular}{lcccc} 
& \multicolumn{3}{c}{ Questionnaire } & \\
\cline { 2 - 4 } Interview & Better & No change & Worse & Total \\
\hline Pain scores & & & & \\
\hline Better & 6 & 1 & 2 & 9 \\
\hline No change & 7 & 2 & 1 & 10 \\
\hline Worse & 1 & 0 & 0 & 1 \\
\hline Total & 14 & 3 & 3 & $20^{*}$ \\
\hline Disability scores & & & & \\
\hline Better & 3 & 4 & 4 & 11 \\
\hline No change & 3 & 2 & 3 & 8 \\
\hline Worse & 1 & 0 & 0 & 1 \\
\hline Total & 7 & 6 & 7 & $20^{*}$
\end{tabular}

${ }^{*}$ Six men and 14 women. Six were aged 45-59; five were aged 60-69, and nine were aged 70 or older.

conducted in patients' homes, guided by a checklist of topics that ensured similar issues were explored. Interviews were taped, fully transcribed, and analysed independently by RC and PD, who were blind to the scores on the scales. For both questionnaire and interview data we recorded whether the patient reported worsening, improvement, or no change in pain and restriction of activities.

The level of concordance between the questionnaire and interview data was less than $50 \%$ (table). Questionnaire data indicated that three patients had increased pain and seven an increased restriction of activities. In contrast, data from the interviews showed that only one patient had increased pain and one increased disability. A similar trend was apparent in the number of patients reporting their symptoms as unchanged. This disparity was particularly marked in pain scores, where questionnaire data showed that pain was unchanged in three patients, whereas interview data indicated this was so for 10 patients. Some patients who showed worsening on pain and scores of the osteoarthritis index considered themselves better, and vice versa.

\section{Comment}

The way in which responses are elicited and the context in which data are recorded can affect reported outcomes in osteoarthritis, potentially leading to erroneous decisions about what interventions benefit patients. Randomised controlled trials need reliable and valid patient based outcome measures to determine whether an intervention is effective.

The lack of agreement in this study between standard patient based measurements and patients' narrative accounts is disquieting. The discrepancies are unlikely to be explained by differences in the timing of the quantitative assessments and interviews, and the investigators agreed completely in the interpretation of the interview data. Furthermore, topics included in the interview guide corresponded to those in the questionnaire of the osteoarthritis index. The most likely explanation comes from the context in which data were collected: the quantitative information was obtained in the trial clinic in the presence of a doctor, whereas the qualitative accounts were obtained by an independent interviewer (who was not a healthcare professional) in the patient's home.

We thank all the patients who participated in the research; Marion Tucker, who provided the physiotherapy intervention; and Jenny Donovan, who commented helpfully on a draft of this paper.

Contributors: RC initiated the study. $\mathrm{PD}$ and $\mathrm{BQ}$ devised the trial from which the patients were recruited, and Maggie Evans conducted the qualitative interviews. BQ undertook the analysis of the data from the quantitative trial and RC and PD the analysis of the data from the in-depth interviews. RC wrote the first draft, with all authors contributing to the writing of subsequent drafts. RC and PD will act as guarantors.

Funding: RS is funded by South and West regional Research Directorate. Both the trial and the qualitative study were funded by grants from the South and West Regional Research Directorate. Paul Dieppe is director of the MRC Health Services Research Collaboration, which is based in the Department of Social Medicine at the University of Bristol.

Competing interests: None declared.

1 Bowling A. Measuring disease: a review of disease-specific quality of life measurement scales. Buckingham: Open University Press, 1995.

2 Streiner DL, Norman GR. Health measurement scales. Oxford: Oxford University Press, 1989

3 Campbell R, Evans M, Tucker M, Quilty B, Dieppe P, Donovan J. Why don't patients do their exercises? Understanding non-compliance with physiotherapy in patients with osteoarthritis of the knee. J Epidemiol Com physiotherapy in patients with

4 Quilty B, Tucker M, Dieppe P. Patello-femoral joint disease. Disability, quadriceps dysfunction and response to physiotherapy. Leeds: NHS Executive, 2001. ((Final report to NHS National Research and Development Programme, Physical and complex disabilities, 1998.) www.doh.gov.uk/research $\mathrm{swro} / \mathrm{rd} / \mathrm{national} / \mathrm{pcd} /$ funded/completed/a1123es.htm (accessed 13 swro/rd/n

5 Bellamy N, Buchanan W, Goldsmith C, Campbell J, Stitt L. Validation study of WOMAC: a health states instrument for measuring clinically important patient relevant outcomes in anti rheumatic drug therapy in patients with osteoarthritis of the knee or hip. J Rheumatol 1988;15:1833-40.

(Accepted 7 August 2002)
Department of Medicine, University of Bristol Brian Quilty consultant in rheumatology

MRC Health Services Research Collaboration, University of Bristol Paul Dieppe director

Correspondence to: R Campbell rona.campbell@ bris.ac.uk

\section{Patient or client?}

It is sometimes claimed that our patients would be more empowered if we referred to them as clients. This assertion does not seem to be altogether logical if one considers the Latin roots of both these words.

Whereas patiens simply denotes someone who is suffering, cliens is derived from the alteration of an earlier form, cluens, from cluere (to listen, follow, or obey). Hence, a client was always listening out for another's orders, unable to take independent action. Client denotes a person of lowly status at another's beck and call and dependent on him.

In ancient Rome clients were plebeians who were bound in a subservient relationship with their patrician patron. Clients acknowledged their dependence on the patron and received his protection in return. Freed slaves automatically became the clients of their former owners. The patron might represent and support them in court (from which is derived the modern use, dating to the 17th century, of calling the customers of lawyers clients); in return, the clients provided services and even money to the patron. Clients were expected to show deference to their patron, especially by calling on him every morning (salutatio). Clients became mockingly known as salutatores. In later periods, client came to denote a beggar and hanger-on.

Is it better to be a sufferer or a toady?

T P S Bloch general practitioner, Barn Close Surgery, Broadway, Worcestershire 